\title{
ALGUMAS CONSIDERAÇÕES SOBRE O PROCESSO DE DESINSTITUCIONALIZAÇÃO
}

\author{
Dora Sadigursky* \\ José Lucimar Tavares*
}

SADIGURSKY, D.; TAVARES, J.L. Algumas considerações sobre o processo de desinstitucionalização. Rev.latinoam.enfermagem, Ribeirão Preto, v. 6, n. 2, p. 23-27, abril 1998.

Este artigo, desenvolve algumas considerações sobre o processo de desinstitucionalização. Para tanto, considera as dificuldades em se reverter a concepção e o estigma da loucura na sociedade, conformada ao longo da história, assim como, a consolidação de uma infra estrutura necessária a esse processo, a qual mantém relação direta com todos os sujeitos sociais e determinações políticas.

UNITERMOS: reforma psiquiátrica, desinstitucionalização

\section{INTRODUÇÃO}

As considerações contidas neste artigo, baseiamse nos resultados de observações advindas da nossa vivência na enfermagem, iniciada nos anos 70 , quando estudantes e, posteriormente enquanto docentes da disciplina enfermagem de saúde mental e psiquiátrica, especialmente, supervisionando alunos em campos de estágio de instituições psiquiátricas da cidade do Salvador.

Ainda como estudantes, desenvolvemos estágios tanto em instituições asilares, quanto naquelas com propostas modernizadoras da assistência. Essas últimas instituições, mesmo com tais propostas, mantinham "seqüelas" decorrentes das práticas da exclusão social, como o seqüestro da cidadania e a violência institucional, o que reforçava o afastamento do doente de seu ambiente familiar, promovendo o afrouxamento das relações e a perda dos laços afetivos.

Ao longo das três últimas décadas, a assistência psiquiátrica tendeu a uma série de transformações oriundas de mudanças ocorridas na própria sociedade e nas políticas de saúde mental. No entanto, essas transformações estão ocorrendo lentamente e de maneira muito aquém da proposta de desinstitucionalização, ora pretendida.

Muitas das tentativas de transformação da instituição psiquiátrica, surgiram no Brasil a partir da década de 80 , buscando a reversão do modelo asilar caótico, segregador e dissocializante, através da luta dos profissionais de saúde mental.

\section{O processo de desinstitucionalização}

A luta anti-manicomial, vem traduzindo os anseios dos profissionais da área, em reinserir o doente mental na sociedade e devolver-lhe a cidadania por tanto tempo negada. Essa luta, tem encontrado uma série de obstáculos que vêm impedindo a sua efetiva implementação no território brasileiro, não sendo raro, ainda nos deparamos com hospitais psiquiátricos, nos quais o modelo asilar predomina.

Esses hospitais, geralmente apresentam estruturas adaptadas, obsoletas, com um grande número de pacientes por unidade, elevada taxa de permanência hospitalar, favorecendo a muitas reinternações e pouca resolutividade. A assistência baseia-se numa terapêutica medicamentosa abusiva visando, sobretudo, o lucro, mantendo a continuidade do sistema de afastamento e de segregação do doente mental da sociedade.

A nossa postura, contrária a esta ideologia, deve ser registrada porém, temos a clareza de que existem ainda situações especiais que torna necessária a alternativa de internação, para aqueles indivíduos que apresentam uma alteração comportamental aguda e que podem acarretar danos não só para si próprio mas, a família e a sociedade em geral.

Sabemos ainda, que alguns pacientes

\footnotetext{
* Docentes da Disciplina Enfermagem de Saúde Mental e Psiquiátrica do Departamento de Enfermagem Médico-Cirúrgica e Administração em Enfermagem, da Escola de Enfermagem da Universidade Federal da Bahia. Doutorandos do Programa Interunidades de Doutoramento em Enfermagem da Escola de Enfermagem de Ribeirão Preto da Universidade de São Paulo
} 
abandonados pela família, passam a ser hóspedes permanentes desses hospitais, o único lugar que os recebem e os acolhem e, onde bem ou mal sobrevivem, apesar dos abusos e descasos do modelo de atenção adotado. Ressaltamos também, que nesses casos, os problemas sociais são mais evidentes do que mesmo a "doença mental" em si.

Por outro lado, fechar as portas destas instituições, sem antes garantir a existência de outras alternativas de assistência para esses indivíduos na comunidade, com capacidade suficiente para atender a demanda existente e de fácil acesso a elas, não nos parece ser uma atitude coerente.

Assim, não devemos ignorar o fato de que em nosso país, há um grande contingente de pessoas sobrevivendo em condições situadas abaixo da linha de pobreza, às quais somam-se os doentes mentais, em especial, aqueles que não recebem os devidos cuidados e atenção, o que os levam à marginalização, engrossando a fileira dos miseráveis, que perambulam pelas ruas de nossas cidades.

Entendemos ainda que, para resolver esta situação, há necessidade de uma organização na sociedade, de modo a respaldar a absorção desse contingente de indivíduos, em cada localidade por serviços de assistência extra-hospitalar, que possuam procedimentos adequados e efetivos promovendo a operacionalização e a utilização racional dos recursos comunitários preconizados pela política de desinstitucionalização, em quantidade e qualidade suficientes, para atender a demanda existente pois, caso contrário, estaremos apenas modificando a nomenclatura, e dando continuidade aos mesmos vícios e propósitos de isolar, segregar, violentar e cassar os seus direitos humanos e de cidadania.

Nossa experiência tem demonstrado que os doentes mentais, que vivem pelas ruas, dormindo ao relento, alimentando-se de restos que recolhem do lixo e realizando suas necessidades fisiológicas em praças públicas, quando começam a importunar a sociedade são, na maioria das vezes, recolhidos por policias que os levam para os hospitais psiquiátricos ou, até mesmo, para prisões.

Essas instituições, não podem retê-los para sempre e assim, logo que se encontrem compensados, são devolvidos para as ruas. Deste modo, a falta de estrutura familiar ou de suporte na comunidade, poderá se traduzir no risco de serem exterminados, à exemplo de tantos outros segmentos marginalizados de nossa sociedade.

Constatamos que nesse contexto, surge o processo de desinstitucionalização no Brasil, respaldado pelo Decreto-lei 3657/1989, de autoria do então deputado Paulo Delgado (PT-MG), com o intuito de por fim à legislação de 1934, ainda em vigor a qual vem direcionando até hoje a assistência psiquiátrica no país, privilegiando sobretudo o modelo segregador e dissocializante do hospital asilar, como único recurso "terapêutico".

Esta proposta, prevê a extinção progressiva dos manicômios, a substituição destes, por uma rede de recursos assistênciais extra hospitalares; a regulamentação da internação psiquiátrica compulsória; a proibição de se construir novos hospitais psiquiátricos em todo território nacional, bem como do financiamento, pelo setor governamental, para a abertura de novos leitos nos hospitais já existentes(BRASIL, 1989).

O marco referencial da desinstitucionalização brasileira, é a Lei 180, da reforma psiquiátrica italiana que demonstrou forte poder de mobilização social, política e cultural, valorizando os direitos de cidadania do doente mental, oferecendo-lhes soluções alternativas de tratamento na comunidade (ROTELLI, 1992; NETO, 1992).

Ainda para ROTELLI (1992), a desinstitucionalização é um processo social complexo, que deve envolver todos os atores sociais, visando modificar a forma de organização das instituições psiquiátricas, criando estruturas que venham substituílas. Isto requer, sem dúvida, a construção de uma nova política para a saúde mental no país.

BARROS (1993) comenta, que a desinstitucionalização da doença mental é aquela que se verificará através do desmonte dos aparelhos que lhes dá sustentação e que podem ser traduzidos pela luta contra a violência, a desmistificação dos preceitos do hospital psiquiátrico e a criação de serviços com uma lógica diferente da exclusão e da opressão.

Necessário se torna porém, expor algumas questões que vêm sendo levantadas por autores com BOTEGA \& DALGALARRONDO (1993), no que diz respeito à experiência da desinstitucionalização italiana e, que valem a pena serem analisadas, antes de nós nos lançarmos a ela, evitando que esses riscos também ocorram em nosso país. Exemplificando temos:

- A população de "doentes crônicos" continuam internados em asilos.

- As Unidades Psiquiátricas em Hospitais Gerais (UPGs) são em número insuficientes para absorver a demanda de pacientes que requerem assistência e, estas estão situadas principalmente ao norte da Itália, região mais próspera do país.

- Há carência de serviços intermediários na comunidade. - A família tem referido queixas, face ao estresse pelo "peso" de cuidar de pacientes crônicos em casa.

- A população psiquiátrica tem aumentado nas prisões porquê, os doentes mentais, sem moradia, ficam nas ruas, possibilitando a ação da polícia. 
- Algumas instituições, continuam com o caráter asilar, apenas com "mudanças aparentes".

Estas constatações, devem nos servir de alerta para não cometermos os mesmos enganos; lembrando ainda que a Itália, embora apresente diferenças entre o norte e o sul do país, possui área e população bem menor que a brasileira, e nível econômico, político e cultural muito diferente do nosso. Deste modo, se não considerarmos tais aspectos, estaremos mais uma vez, copiando teoricamente o modelo de um país de primeiro mundo cuja realidade é diversa da nossa.

Deve ser analisado também, que normalmente é atribuída à instituição psiquiátrica a "culpa" de ter assumido a responsabilidade pela custódia dos "loucos", isolando-os da comunidade. Atualmente, esta mesma instituição, quer devolvê-los com a proposta de que a comunidade redefina as concepções sobre a loucura e, os acolham novamente de modo espontâneo (LOUGON, 1993)

Ora, este é um aspecto que necessita ser trabalhado na sociedade pois, o ideário sobre a loucura é o da incurabilidade e periculosidade, estigmas que são difíceis de serem revertidos de uma hora para outra!

Ainda LOUGON (1993) fazendo uma análise crítica à desinstitucionalização, refere que ao se colocar o hospital como único culpado por esse estado de degradação em que se encontram os doentes mentais, não se reconhece a importância da evolução de certas "doenças" que estes indivíduos apresentavam, antes de serem internados. Assim, acredita que desconhecer a existência de comportamentos que fogem aos padrões comuns considerados, pela clinica, como doença é o que, para este autor, pode gerar uma série de equívocos, sendo o maior deles, talvez, a idéia de que basta colocar o indivíduo na sociedade para ele, automáticamente, readquirir sua condição de cidadão.

Sabemos que isso é uma "falácia" pois, mesmo "compensado", para a sociedade o indivíduo será sempre o "louco" porque o estigma, ainda é fato extremamente expressivo, para ser tão repente banido do imaginário coletivo.

Para CAVALCANTI (1993) existem muitos indivíduos que continuam tendo a necessidade de um suporte na comunidade para terem acesso a moradia e alimentação, principalmente, quando não mais possuem referência familiar.

Um outro aspecto que também nos chama atenção, é o de que embora, se preconize a existência de leitos psiquiátricos em hospitais gerais, são poucos os serviços desta natureza em nosso país. Deste modo, os indivíduos continuam sendo confinados em casas "especializadas", que não oferecem atendimento humanizado e terapêutico efetivo para essa clientela (LANDMANN, 1982).
A idéia de que o hospital psiquiátrico, é o lugar mais adequado para o tratamento e "cura" do doente mental ou simplesmente para sua permanência, cria e propaga na comunidade uma resistência inercial, dificultando a reintegração dos pacientes desses hospitais (LOUGON, 1993).

Esse autor, ainda comenta que para se implementar o processo de desinstitucionalização, devese procurar antes de tudo saber quais são os indivíduos que devem e podem ser de fato desinstitucionalizados: se todos os internos em asilos, ou apenas aqueles que, por características demográficas ou diagnósticas necessitam receber tratamento na comunidade, ou ainda aqueles que foram inadequadamente hospitalizados.

Ainda para este mesmo autor, a desinstitucionalização implica em investimentos de outros recursos e modelos de assistência pois, o simples fechamento das portas das instituições asilares não garantem a oferta de outras alternativas para a clientela que necessita de tratamento de longa duração ou mesmo custódia.

TSU (1993) considera que, para os familiares, esse processo tem se constituído um descumprimento do Estado de sua obrigação. Os discursos a esse respeito, não têm sensibilizado as famílias carentes, de que é melhor para elas e para o paciente, o tratamento em casa e, diante desses fatos, a família conclui que deve lutar por uma guia de internação.

A rejeição familiar com relação ao doente mental é, de certo modo, esperada principalmente, quando este fica por muito tempo afastado por força de internações ou pelo número elevado de reinternações, o que promove fragmentações das interrelações familiares (SGAMBATI, 1983).

Uma grande preocupação dessa autora, é saber se a família e a comunidade estão preparadas para absorver o encargo de cuidar do indivíduo em casa, o que é também pretendido pela desinstitucionalização e, se o aumento das altas hospitalares, será acompanhado do crescimento de outros serviços assistências na comunidade para atender tal demanda.

Também para VENÂNCIO (1993), a idéia de manter o paciente vinculado à sociedade, deve vir acompanhada de recursos alternativos na comunidade que garanta a intermediação do processo de reinserção social do doente mental, visando o seu tratamento, sem necessariamente, ter de interná-lo.

MORGADO \& LIMA (1994) concordam, que para tal investida, é necessário implantar-se uma infra estrutura complexa e dispendiosa na comunidade para atender a todos os indivíduos pois, sem ela, ocorrerá mera desospitalização, onde os pacientes ficarão fora do hospital, possivelmente nas ruas, sem que se tenha lhes assegurado uma existência digna. 
Considerando o até então exposto, temos que a luta antimanicomial, se bem entendida, não consiste em por abaixo ou "arrasar" materialmente o manicômio mas, atuar como um movimento que modifique as práticas e a cultura psiquiátrica dominante (CAMPOS, 1992).

No nosso entender, se a sociedade não estiver devidamente organizada neste sentido, tal processo deverá ser realizado por etapas, até pela reeducação social pois, caso contrário, correremos o risco de aumentar o caos, sem de fato reintegrar os "diferentes".

A reversão do atual modelo de atenção psiquiátrica, só se efetivará a partir de uma decisão política, creditada a todos: pacientes, familiares, trabalhadores de saúde mental e a sociedade em geral, senão, trabalharemos de forma estéril na consolidação do proposto.

Vemos ainda que, se a desinstitucionalização não for avaliada por todos os ângulos, se transformará em uma ação paliativa e numa desobrigação do Estado, da responsabilidade para com a saúde coletiva, o que é uma das suas prerrogativas, até então assumidas.

Lembramos também que, a legislação de outrora era direcionada para a institucionalização do doente mental com o objetivo de tratá-lo ainda que às custas do seu isolamento e privação de sua cidadania. Esta idéia, parece não ter surtido o efeito desejado. Atualmente, a legislação vem reforçando a desinstitucionalização com o argumento de tratar o doente mental, só que agora em sentido inverso; na comunidade, como cidadão, devendo ser inserido na sociedade mas, sem prepará-la para aceitar de volta aquele a quem rechaçou no passado.

Concordamos com TSU (1993), quando refere que a desinstitucionalização deve se preocupar com as reais necessidades dos indivíduos e, não apenas, com o fato de reduzir gastos sociais e divulgar uma imagem modernizadora da instituição psiquiátrica. O preconizado só será possível se houver uma real melhoria das condições gerais de vida da população.

Concluímos acrescentando a essa idéia, que deve ser intrínseco ao processo de desinstitucionalização, o estabelecimento de meios que melhorem de fato as condições básicas de vida do paciente e da família; a necessidade de capacitar trabalhadores para lidar com essa nova perspectiva de tratamento; além de se buscar modificar a concepção de loucura em todos os segmentos sociais envolvidos, e também a idéia de que o tratamento do "louco" só pode se dar com o seu confinamento em hospitais psiquiátricos.

\section{SOME CONSIDERATIONS ABOUT THE DEINSTITUTIONALIZATION PROCESS}

This study develops some considerations about the deinstitutionalization process considering the conception and stigma of madness, and the difficulties to reverse it in society as it was constructed through history. Authors analyse the consolidation of the necessary infrastructure to this process, making direct relations with all social subjects and policy determination.

\section{ALGUNAS CONSIDERACIONES SOBRE EL PROCESO DE LA DESINSTITUCIONALIZACIÓN}

Este artículo presenta algunas consideraciones sobre el proceso de la desinstitucionalización. De esta manera,considera la dificultad de reversión de la concepción y del estigma de la locura en la sociedad, conformada a lo largo de la historia, asi como la consolidación de la infra-esctrutura necesaria a este proceso, la cual mantiene relación directa con todos los sujetos sociales y las determinaciones políticas.

TÉRMINOS CLAVES: reforma psiquiátrica, desinstitucionalización

\section{REFERÊNCIAS BIBLIOGRÁFICAS}

01. BARROS, D.D. Desinstitucionalização: cidadania versus violência institucional. Saúde Debate, $n$. 4, p. 68-76, set. 1993.

02. BotegA, J.; DAlGalarRondo, P. Saúde mental no Hospital Geral: espaço para o psiquico. São Paulo: HUCITEC, 1993. 116p.

03. BRASIL. Câmara dos Deputados. Projeto de lei n. 3657. Brasilia, DF, $1989.01 \mathrm{p}$.
04. CAMPOS, F.C.B. Considerações sobre o movimento de reforma dos serviços de saúde mental. Saúde Debate, n. 35, p. 77-9 jul. 1992.

05. CAVALCANTI, M.T. Transformações na assistência psiquiátrica ou uma assistência psiquiátrica em transformação. In: SILVA FILHO, J.F.; RUSSO, J.(orgs.) Duzentos anos de psiquiatria. Rio de Janeiro. Relume-Dumará, 1993. p.145-155.

06. LANDMANN, J. Evitando a saúde e promovendo a doença: o sistema de saúde no Brasil. Rio de Janeiro: Achiamé, 1982. 188 p. 
07. LOUGON, M. Desinstitucionalização da assistência psiquiátrica: uma perspectiva crítica. Rev. Saúde Coletiva, Rio de Janeiro, v.3, n. 2, p.137-164, 1993.

08. MORGADO, A.; LIMA, L. A Desinstitucionalização: suas bases e experiência internacional. J. Bras. Psiquiatria, v.1, n.43, p.19-28,1994.

09. NETO, A. A reforma psiquiátrica no Rio Grande do Sul: do direito ao tratamento aos direitos de cidadania do doente mental. Saúde Debate, n.37, p. 5-10, dez. 1992.

10. ROTELLI, F. et al. Desinstitucionalização uma outra via: a reforma psiquiátrica italiana no contexto da Europa Ocidental e dos países avançados. In: NICÁCIO, F. (org.). Desinstitucionalização. São Paulo: HUCITEC, 1990. p. 17-59.
11. . A experiência da desinstitucionalização italiana: o processo Trieste. Saúde Debate, n.2, jun. 1992. (Cadernos Polêmicos)

12. SGAMBATI, E.V.R. Reinternação e rejeição familiar: um estudo com o paciente psiquiátrico, Ribeirão Preto, 1983. Dissertação(Mestrado) Escola de Enfermagem de Ribeirão Preto, Universidade de São Paulo.

13. TSU, T.A. A internação psiquiátrica e o drama das famílias. São Paulo: EDUSP/VETOR, 1993. $75 \mathrm{p}$.

14. VENÂNCIO, A.T.A. A construção social da pessoa e da psiquiatria: do alienismo a "Nova Psiquiatria”. Physis.Rev. Saúde Coletiva, Rio de Janeiro, v.3, n.2, p. 117-135, 1993. 